\author{
Eleonora Ferraris \\ Nadia Marzocchi \\ Daria Brovia \\ Carmela N. Castellana \\ Luigi A. Pini
}

\section{Homocysteine levels and cardiovascular disease in migraine with aura}

Received: 1 July 2002

Accepted in revised form: 4 December 2002

E. Ferraris • N. Marzocchi • D. Brovia

C.N. Castellana $\bullet$ L.A. Pini $(\bowtie)$

Department of Internal Medicine,

Toxicology and Clinical Pharmacology

Service, Headache Study Centre,

University of Modena and Reggio Emilia,

Via Del Pozzo 71, I-41100 Modena, Italy

e-mail: pinila@unimore.it

Tel: +39-059-4224065

Fax: +39-059-4224069

\begin{abstract}
Clinical studies suggest that hyperhomocysteinemia could be considered an independent risk factor for premature cerebral, peripheral and vascular diseases. A number of authors found an epidemiological correlation between increased risk of cerebrovascular disease and migraine with aura. In this study, 34 patients suffering from migraine with aura and 36 healthy controls were evaluated with respect to total plasma homocysteine levels, measured with FPIA immunoassay in the fasting state and after methionine load.
\end{abstract}

Moreover, vitamin B12, folate and other classic biochemical indicators of atherosclerosis disease were evaluated. In this study, homocysteine levels, both at basal and after load, and other cardiovascular risk factors such as vitamin B12 and apo-LpA were within the normal range. Other multicentric randomised trials are needed to carry on and confirm these data.

Key words Migraine $\cdot$ Aura Hyperhomocysteinemia • Cardiovascular risk

\section{Introduction}

Several clinical and epidemiological studies have suggested that hyperhomocysteinemia is an independent risk factor for premature cerebral stroke, peripheral and vascular diseases (e.g. vasoconstrictive diseases, infarction, ischemia) [1-6]. Patients with these pathologies show plasma homocysteine levels higher than normal (Table 1).

There is increasing evidence that hyperhomocysteinemia may affect the coagulation system and the resistance of endothelium to thrombosis and that it may interfere with the vasodilator and antithrombotic functions of nitric oxide. Elevated plasma homocysteine may pose an oxidative stress, leading to the development of vascular damage through both direct and indirect pathways [7]. In fact, antioxidant plasmatic capacity shows a positive correlation with homocysteine plasma levels. Moreover, this factor is correlated with the production of endothelial nitric oxide, a factor of vasculopathic risk and, at the same time, involved in migraine pathogenesis [8].
Some authors [9-13] have found the existence of an epidemiological correlation between an increased risk of cerebrovascular disease and migraine with aura. The hypothesis is that ischemia is caused by an alteration of specific coagulation factors, such as antiphospholipid antibodies (aPLs), circulating immunoglobulins with prothrombotic effect [14]. Moreover, in migraine subjects a prevalence of elevated levels of lipoprotein A (>300 mg/l) was found with no significant difference between patients with and without aura [15].

Homocysteine plasma levels after methionine oral loading $(100 \mathrm{mg} / \mathrm{kg})$ may help identify alterations in methionine metabolism, also in subjects with normal homocysteine plasma levels at baseline, and may predict a higher vascular disease frequency in migraneous patients, in particular with aura [16].

Boushey et al. [17] showed, in a meta-analysis of 27 studies, that post-methionine load and fasting hyperhomocysteinemia are independent of each other in the majority of individuals, and that without methionine loading 27\%-40\% 
Table 1 Causes of hyperhomocysteinemia

Inherited

Methylene tetrahydrofolate reductase deficiency

Cystathionine b-synthase deficiency

Cobalamine reductase deficiency

Methyltransferase and cobalamine reductase deficiencies

Cystathioninase deficiency

Methionine synthase defect

Cobalamine transport defect

Efflux lysosomal syndrome

Acquired

Demographics: age / sex (> age, male, menopause)

Medications

Folate antagonists (methotrexate, anticonvulsants, isoniazide)

Vitamin B6 antagonists (theophylline)

Chronic diseases

Endocrine (hypothyroidism)

Other diseases (chronic renal failure, psoriasis, heart and other organ transplantations)

Malignancies: ovary, pancreas, lung cancer; acute lymphoblastic leukemia

Vitamin deficiencies: folic acid, vitamin B6, vitamin B12

Lifestyle: smoking, excess of alcohol and coffee intake, lack of exercise

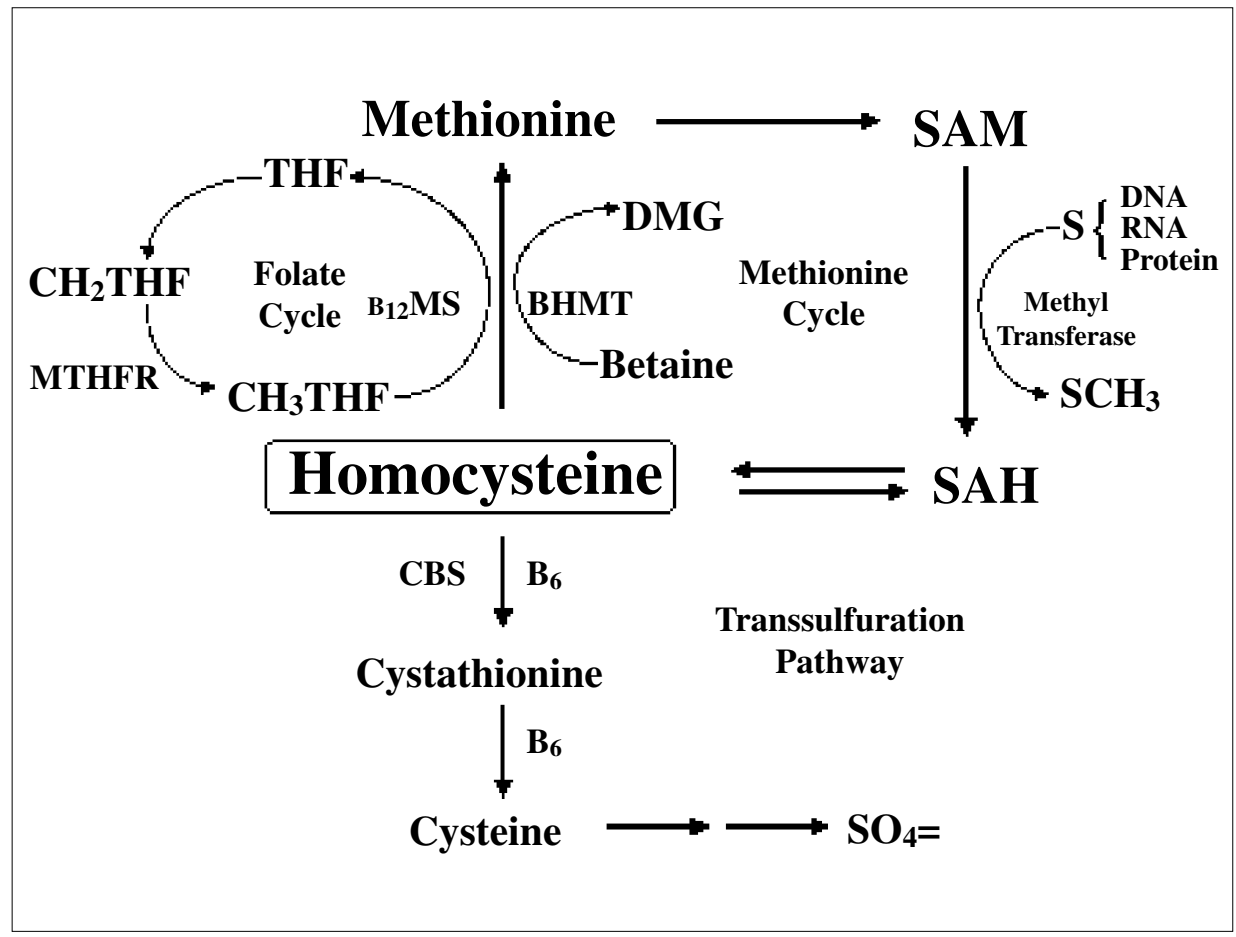

Fig. 1 Homocysteine metabolism 
of the cases of elevated plasma homocysteine could be missed. Hyperhomocysteinemia can be caused by genetic defects (relative or absolute decreases in the enzymes driving the biochemical reactions) or nutritional deficiencies as reported in Table 1.

Homocysteine is an intermediate amino acid formed during the metabolism of methionine, an essential sulfur-containing amino acid supplied from dietary proteins. A large complex of enzymes and cofactors (vitamin B12, B6 and folate) is necessary to maintain homocysteine at normal serum levels (Fig. 1).

In this study we evaluated the homocysteine levels in patients suffering from migraine with aura and in normal subjects, to detect possible alterations of homocysteine plasma levels at basal time and after methionine oral load. At the same time, we collected information about "classic" plasmatic markers of cardiovascular risk.

\section{Materials and methods}

Patients and controls

We recruited 34 migraine patients (Table 2), evaluated in the intercritical period, 12 men and 22 women, aged 18-60 years (mean, 37.8 years; $\mathrm{SD}=11.8$ years) from the Headache Center at our hospital; $6 \%$ of patients were smokers. The mean body mass index was $24.28 \mathrm{~kg} / \mathrm{m}^{2}\left(\mathrm{SD}=4.32 \mathrm{~kg} / \mathrm{m}^{2}\right)$. Mean blood pressure was $127 \pm 18 \mathrm{mmHg}$ (systolic) and $83 \pm 12 \mathrm{mmHg}$ (diastolic). $18 \%$ of patient's relatives referred migraine (5\% with aura) and only $10 \%$ of women assumed oral contraceptives. The diagnosis of migraine with aura (MwA) was performed according to the International Headache Society (IHS) classification [20]. The frequency of attacks ranged between 3 and 20 per year, with an average of 5 attacks/year.
A total of 36 healthy age- and sex-matched volunteers comprised the control group (11 men and 25 women); mean age was 42.1 years $(\mathrm{SD}=12.6$ years $)$.

\section{Biochemical data}

Total plasma homocysteine levels were measured with FPIA immunoassay ( $\operatorname{Imx}$ Abbott Analyzer) both in the fasting state (baseline, time 0) and after methionine load (4 h) [21-23]. Hyperhomocysteinemia $2-8 \mathrm{~h}$ after an oral methionine load (standard dose, $0.1 \mathrm{~g} / \mathrm{kg}$ body weight of L-methionine mixed in fruit juice) may identify individuals at increased risk for vascular disease despite normal fasting total plasma homocysteine concentrations (an additional $27 \%$ of at-risk cases).

Hyperhomocysteinemia is usually defined by using an arbitrary cut-off; normal plasma homocysteine levels range from 5 to $13 \mu \mathrm{mol} / \mathrm{l}$. Men have higher concentrations of homocysteine than women $(1 \mu \mathrm{mol} / \mathrm{l})$, and amounts of homocysteine tend to increase slightly with age [24].

Clinical information was obtained by a direct interview from all the patients responding to questionnaire items on other risk factors: body mass index (BMI), cardiovascular disease, hypertension (basal blood pressure, BP), diabetes mellitus, smoking, familiar history of premature cardiovascular disease or migraine, and actual use of medication (e.g. oral contraceptives) (Table 2).

In addition to the classic lipid levels (total cholesterol, HDLcholesterol, LDL-cholesterol, triglycerides), we also evaluated other risk factors for atherosclerosis, such as apolipoproteins A1 and $\mathrm{B}$, fibrinogen, vitamin $\mathrm{B} 12$ and folate. These have a significant role as nutrients which impact on homocysteine metabolism.

Statistical analysis

Data were analysed using the $t$ test, and are expressed as mean and standard deviation in tables and text.

Table 2 Characteristics of patients and controls

\begin{tabular}{|c|c|c|c|c|c|c|c|}
\hline & $\begin{array}{l}\text { Age, } \\
\text { years }^{\text {a }}\end{array}$ & $\begin{array}{l}\text { Smoking } \\
\text { habit, } \mathrm{n}\end{array}$ & $\begin{array}{c}\text { BMI, } \\
\mathrm{kg} / \mathrm{m}^{2} \mathrm{a}\end{array}$ & $\begin{array}{c}\text { Systolic } \\
\text { blood pressure } \\
>145 \mathrm{mmHg} \\
\mathrm{n}\end{array}$ & $\begin{array}{c}\text { Diastolic } \\
\text { blood } \\
\text { pressure } \\
>95 \mathrm{mmHg}, \mathrm{n}\end{array}$ & Familiarity, $\mathrm{n}^{\mathrm{b}}$ & $\begin{array}{c}\text { Oral } \\
\text { contraceptives } \\
\text { use, } \mathrm{n}\end{array}$ \\
\hline $\begin{array}{l}\text { Migraine } \\
\text { with aura } \\
(n=34)\end{array}$ & 37.79 (11.82) & 4 & $24.28(4.32)$ & 3 & 4 & 7 & 3 \\
\hline Controls $(\mathrm{n}=36)$ & $42.1(12.6)$ & 3 & $25.54(5.37)$ & 2 & 1 & 6 & 4 \\
\hline
\end{tabular}

a Values are expressed as mean (SD)

${ }^{\mathrm{b}}$ Parents and first-degree relatives for stroke and myocardial infarction

$B M I$, body mass index 
Table 3 Homocysteine plasma levels in migraine patients and controls. Values are mean (SD) expressed in micromolar

\begin{tabular}{lrr}
\hline & \multicolumn{1}{c}{ Baseline } & Post-load \\
\hline Migraine with aura & $11.08(3.57)$ & $30.32(9.27)$ \\
Controls & $12.8(6.01)$ & $31.05(7.42)$ \\
$p$ & NS & NS \\
\hline
\end{tabular}

$N S$, not significant

Table 4 Plasmatic cardiovascular risk factors in patients and controls. Values are mean (SD). Two patients and two controls were aged over 60 years. Both patients' and control's biochemical parameters fell into the normal ranges

\begin{tabular}{lccccccccc}
\hline & $\begin{array}{c}\mathrm{B} 12, \\
\mathrm{pg} / \mathrm{ml}\end{array}$ & $\begin{array}{c}\text { Folate, } \\
\mathrm{ng} / \mathrm{dl}\end{array}$ & $\begin{array}{c}\mathrm{ApoA}, \\
\mathrm{mg} / \mathrm{dl}\end{array}$ & $\begin{array}{c}\mathrm{ApoB}, \\
\mathrm{mg} / \mathrm{dl}\end{array}$ & $\begin{array}{c}\mathrm{CHOL}, \\
\mathrm{mg} / \mathrm{dl}\end{array}$ & $\begin{array}{c}\mathrm{HDL}, \\
\mathrm{mg} / \mathrm{dl}\end{array}$ & $\begin{array}{c}\text { LDL, } \\
\mathrm{mg} / \mathrm{dl}\end{array}$ & $\begin{array}{c}\text { TRIG, } \\
\mathrm{mg} / \mathrm{dl}\end{array}$ & $\begin{array}{c}\text { Fibrin, } \\
\mathrm{mg} / \mathrm{dl}\end{array}$ \\
\hline Controls & $350(143)$ & $8.0(4.5)$ & $107.0(34.4)$ & $105.0(32.6)$ & $194(48)$ & $64.0(18.3)$ & $130(45.3)$ & $118(48.6)$ & $315(31.4)$ \\
$\begin{array}{l}\text { Migraine } \\
\text { with aura }\end{array}$ & $374.4(194.1)$ & $5.93(3.37)$ & $112.6(28.21)$ & $93.5(27.2)$ & $206.7(38.9)$ & $54.7(13.4)$ & $119(39.7)$ & $94.5(40.3)$ & $278.9(41.0)$ \\
\end{tabular}

CHOL, cholesterol; TRIG, triglycerides

\section{Results}

A baseline homocysteine level higher than $13 \mu \mathrm{mol} / \mathrm{l}(<13$ under 60 years, $<20$ over 60 ) or a pathological difference between the basal value and the post-load value $(>27$ $\mu \mathrm{mol} / \mathrm{l})$ is considered an indicator of high risk for cardiovascular disease. In Table 3, we report the homocysteine data of our patients.

The others plasmatic parameters of cardiovascular risk are reported in Table 4.

\section{Discussion}

Although there is evidence from epidemiological studies supporting a positive relationship between elevated plasma homocysteine and coronary heart disease, and between migraine and stroke (in women, under 45 years of age [11, 12]), these studies are inconsistent and not univocal, because of differences in study design, methodological or statistical power and chance (publication bias) [2]. It remains to be demonstrated that reducing elevated plasma homocysteine levels will result in a reduction in the risk for cardiovascular disease. Moreover, the definition of elevated homocysteine levels is not standardized, and substantial differences exist in the "normal" reference used in the literature (day-to-day, postprandial, orthostatic, intra- and inter-individual variations).

In this study, despite the small series, we found no significant difference between migraine with aura patients and controls with respect to episodes of stroke or other vascular diseases. Only in one case was homocysteine over the normal range. The patient was a 45 -year-old woman suffering from migraine with prolonged aura, with a familial history of migraine and diabetes mellitus, but not for myocardial infarction or stroke. Her lifestyle was free from alcohol and tobacco smoke, dietary intake was correct, and neuroimaging results were normal.

There are reports suggesting that vitamins are related to progression of atherosclerosis and variation of circulating homocysteine $[17,18]$. Therefore, the use of folic acid, vitamin B6 and B12 supplementation was proposed to normalize the pathologically high homocysteine levels, although there is no clear evidence that treatment with vitamins alters progression of atherosclerosis or reduces cardiovascular events [17-19].

In our study homocysteine levels and other cardiovascular risk factors such as vitamin B12 and apo-LpA were within the normal ranges and were not related to the presence of migraine with aura. Although this study shows a negative relationship between migraine with aura and homocysteine, in the literature there are some reports referring these correlations. The association between homocysteine levels and migraine is less documented than that between migraine and stroke. Therefore, careful multicentric randomized trials with a large number of patients are needed to establish whether migraine with aura may be associated with a significant risk for cardiovascular disease and, in case of positive results, to define the prognostic and predictive values of serum homocysteine in these patients. In conclusion, lacking positive evidence, this test has no pathognomonic indication in patients suffering from migraine with aura. 


\section{References}

1. Hankey GJ, Eikelboom JW (1999) Homocysteine and vascular disease. Lancet 354:407-413

2. Christen WG, Ajani UA, Glynn RJ, Hennekens CH (2000) Blood levels of homocysteine and increased risks of cardiovascular disease: causal or casual? Arch Inter Med 160:422-434

3. Eikelboom JW, Lonn E, Genest JJ, Hankey G, Yusuf S (1999)

Homocysteine and cardiovascular disease: a critical review of the epidemiological evidence. Ann Intern Med 131:363-375

4. Wald NJ, Watt HC, Law MR, Weir DG, McPartlin J, Scott JM (1998) Homocysteine and ischaemic heart disease. Arch Intern Med 158:862-867

5. Alfthan G, Aro A, Gey KF (1997) Plasma homocysteine and cardiovascular disease mortality. Lancet 349:397

6. Nygard O, Nordrehaug JE, Refsum H et al (1997) Plasma homocysteine levels and mortality in patients with coronary artery disease. $\mathrm{N}$ Engl J Med 337:230-236

7. Moat SJ, Bonham JR, Powers HJ (2001) Role of aminothiols as a component of the plasma antioxidant system and relevance to homocysteinemediated vascular disease. Clin Sci 100:79

8. Zhang X, Li H, Jin H et al (2000) Effects of homocysteine on endothelial nitric oxide production. Am J Physiol Renal Physiol 279:671-678

9. Schlesinger I, Hering R (1997) Homocysteine levels in migraine patients. Cephalalgia 17:46
10. Carolei A, Marini C, De Matteis G (1996) History of migraine and risk of cerebral ischaemia in young adults. Lancet 347:1503-1506

11. Merikangas KR, Fenton BT, Cheng SH, Stolar MJ, Risch N (1997) Association between migraine and stroke in a large-scale epidemiological study of the United States. Arch Neurol 54:362-368

12. Tzourio C, Kittner SJ, Bousser M-G, Alpèrovitch A (2000) Migraine and stroke in young women. Cephalalgia 20:190-199

13. Hering-Hanit R, Gadoth N, Yavetz A, Gavendo S, Sela B (2001) Is blood homocysteine elevated in migraine? Headache 41:779-781

14. Silvestrini M (1996) Migrainous stroke and antiphospholipid antibodies. Are they pathogenetically linked? Eur Neurol 36(2):114

15. Hering-Hanit R, Friedman Z, Schlesinger I, Ellis M (2001) Evidence for activation of the coagulation system in migraine with aura. Cephalagia 21:137-139

16. Tsai MJ, McGovern P, Kennedy EL, Hanson NQ (2001) Short-term variability in the measurement of plasma homocysteine, fasting and post-methionine loading. Clin Biochem 34:49-52

17. Boushey CJ et al (1995) A quantitative assessment of plasma homocysteine as a risk factor for vascular disease. JAMA 274:1049-1057

18. Adams AK, Wermuth EO, McBride PE (1999) Antioxidant vitamins and the prevention of coronary heart disease. Am Fam Physician 60:385-904
19. Clarke R, Armitage J (2000) Vitamin supplements and cardiovascular risk: review of the randomized trials of homocysteine-lowering vitamin supplements. Semin Thromb Hemost 26:341-348

20. Peterson JC, Spence JD (1998) Vitamins and progression of atherosclerosis in hyper-homocysteinaemia. Lancet 351:263

21. - (1988) Classification and diagnostic criteria for headache disorders, cranial nevralgias and facial pain. Headache Classification Committee of the International Headache Society. Cephalagia 8[Suppl 7]:1-96

22. Ubbink JB, Delport R, Riezler R, Hayward Vermaak WJ (1999) Comparison of three different plasma homocysteine assays with gas chromatography-mass spectrometry. Clin Chem 45:670-675

23. Pfeiffer CM, Twite D, Shih J, HoletsMcCormack SR, Gunter EW (1999) Method comparison for total plasma homocysteine between the Abbott Imx Analyzer and an HPLC assay with internal standardization. Clin Chem 45:152-153

24. Thirup P, Ekelund S (1999) Day-today, postprandial, and orthostatic variation of total plasma homocysteine. Clin Chem 45:1280

25. Pincemail J, Siquet J, Chapelle JP et al (2000) Determination of plasma concentrations of antioxidants, antibodies against oxidized LDL, and homocysteine in a population sample from Liege. Ann Biol Clin 58:177-185 